\title{
Multinational Corporations and Industrial Employment
}

\author{
Hamid Beladi and Ralph Frasca* \\ University of Dayton
}

\begin{abstract}
The paper is to present a theory consistent with the stylised facts that employment and wages in the manufacturing sectors of the developed nations decline. It focuses on a world of multinational corporations where capital and technology are increasingly mobil.
\end{abstract}

- JEL Classifications: F10, F2, F23

- Key Words: Factor Mobility, Multinational Corporations, Wages

\section{Introduction}

Theories of international trade that highlight structural changes should be consistent with the following facts and trends. ${ }^{1}$

1. Since 1973 there has been either stagnation or decline in real hourly earnings of non-supervisory manufacturing workers in the developed nations.

2. In the developed nations the ratio of manufacturing to non-manufacturing workers has declined significantly, and wages of the least skilled workers have followed that decline.

3. The industrialized nations have exhibited a decrease in manufacturings share of GDP, and a concurrent expansion in the services sector.

4. Labor force rates of growth among the less advanced nations are greater than in the developed nations, and there are significant barriers to the international

\footnotetext{
*Corresponding Address: Hamid Beladim, Department of Economics \& Finance 300 College Park, Daton, Ohio USA 45469-2251. Tel: +1-937-229-2407, Fax: +1-937-229-4745, Email: beladi@udayton.edu

Ralph Frasca, Tel: +1-937-229-2405, Fax: +1-937-229-2477, Email: frasca@udayton.edu

${ }^{1}$ These facts have been repeatedly mentioned in the trade literature. Batra (1992) discusses facts 1 and 3 and part of 4 .

(C)2000-Center for International Economics, Sejong Institution, all Rights Reserved.
} 
movement of labor.

The primary purpose of this paper is to present a theory that is consistent with the stylized facts and that offers a reasoned explanation for the ongoing structural changes in the international economy. These generally recognized facts have generated heated debates concerning the relevant causes. The major point of contention concerns the causal factors generating the relative decline in employment and wages in the manufacturing sectors of the developed nations. On one side of the issue are those, like Krugman (1995), who argue that the structural changes occurring in the developed nations are the result of internal technological forces. On the other side are Jones and Engerman (1996), who suggest that international forces have significantly contributed to the changes in employment and wages among the developed nations.

Our model pursues an alternative explanation for the stylized facts. It focuses on a world of multinational corporations in which capital and technology are increasingly mobile. This is reflected in the growing research on the theory of multinational enterprise (Markusen, 1995). By functioning in both the developed and the developing nations, multinational firms can relocate capital to wherever markets are most advantageous. Within this context, changes in exogenous variables can initiate movements in capital and technology that may have both a short-run and a long-run impact on the world's economies. Arguments that attempt to explain current trends in terms of only changes in technology in the developed nations, or only changes in the volume of trade, are ignoring the existing interrelationships between capital, technology and trade. Once we stress the endogenous nature of these variables, we must then search for truly exogenous variables. In the accompanying model, labor growth is the determining factor. In this world of multinational firms and capital mobility, faster labor growth in the third world can reinforce the observed trends in employment and wages.

The general equilibrium model of production that is traditionally used in trade theory is the Heckscher-Ohlin (H-O) model where capital and labor are immobile internationally. $^{2}$ Batra and Ramachandran (B-R) (1980) provided a general equilibrium model incorporating multinational firms. ${ }^{3}$ Among other things, they show how tariffs and internal taxes play an intricate role in the decision-making of the global firms.

\footnotetext{
${ }^{2}$ See for example Chao and Yu (1990, 1992) and Yu (1982).

${ }^{3}$ For more theoretical analyses of international capital movements and direct foreign investment see Jones (1967, 1987) and Beladi and Marjit (1994). For other recent articles on the subject see Markusen (1995).
} 
In this paper we build upon the stream of research generated by the B-R model and analyze the impact of a change in the factor supply at constant product prices, much like the Rybczynski Theorem in the H-O model. The conclusions in the multinational world turn out to be quite different. Our results are compatible with the real wage and employment puzzle noted by many labor economists and more recently by trade theorists as well. The puzzle concerns the fall in the manufacturing employment, as well as, the real wage in the United States. The following model suggests that faster labor growth in the third world, where the global firms have recently located their operations, is one explanation for reduced real wage growth in the U.S. The models and the results depict the situation in Japan, Australia and the U.S. The results also readily apply to the "Little Dragons" in East Asia, Hong Kong in particular. While Hong Kong has experienced a relatively high growth rate, its manufacturing employment is shrinking, as a result of large scale direct investment undertaken inside China mainland. Concomitantly, labor force grows faster in the mainland than Hong Kong, another key feature of this paper, hence, the result predicted by the model in this paper.

This paper is divided into four sections. In the second and third sections we discuss the model and the results; whereas, in the last section we conclude the paper with some suggestions for future research in this area.

\section{The Model}

Let us assume that we have two countries, a source country which is the home of multinational corporations and a host country which is foreign to the global corporations. ${ }^{4}$ Each country has two sectors, one in which multinational firms actively compete (the manufacturing sector) and the other in which only local firms operate (the services sector). Both countries are small relative to total world trade and the relative prices of the sectoral outputs are determined exogenously. Capital is specific to both sectors: whereas, labor is the only non-specific factor. The production function of the global firms also contains one specific factor, $S$, which may be construed as special managerial skills, know-how, entre-preneurship, patents, etc. Production functions are linearly homogenous and quasiconcave and producers face perfect competition in product and factor markets. Full employ-ment and inelastic factor supplies are also assumed. Given these

${ }^{4}$ For a detailed and comprehensive analysis of foreign capital and multinational corporations see Batra (1986), Marjit and Beladi (1996, 1997), Beladi and Marjit (1994, 1996), and Yu (1985). 
assumptions, the production side of the model is described by the following equations,

$$
\begin{gathered}
X=X\left(K_{x}, L_{x}, S\right) ; X^{*}=X^{*}\left(K_{x}^{*}, L_{x}^{*}, S^{*}\right) \\
Y=Y\left(K_{y}, L_{y}\right) Y^{*}=Y^{*}\left(K_{y}^{*}, L_{y}^{*}\right)
\end{gathered}
$$

where $X$ and $Y$ are the sectors in which the multinational and the local firms produce their products respectively. As inputs in the production process, $(K)$ stands for capital, $(L)$ for labor and $(S)$ for the specific factor. Star denotes the variables in the host country. The production functions are concave and homogenous of degree one, and satisfy the following properties.

In sector $X$, we have,

$$
G_{x}=\left[X_{L L} X_{K K}-X_{K L}^{2}\right]>0 ; X_{j}>0 ; X_{j j}<0 ; X_{j k}>0 \quad(j, k=K, L, S: j \neq k)
$$

whereas, in sector $Y$, we have,

$$
G_{y}=\left[Y_{L L} Y_{K K}-Y_{K L}^{2}\right]=0 ; Y_{j}>0 ; Y_{j j}<Y_{K L}>0 \quad(j=K, L)
$$

Furthermore, similar properties would apply to $X^{*}$ (.) and $Y^{*}($.).

Let $P$ be the relative price of $X$ in terms of $Y$, which is given by the world market. With competitive markets, firms take the rental of capital $(r)$ and the wage rate $(w)$ in both countries as given. The profits of multinational firms from their operations in the source country and the host country are stated by:

$$
I I=\left(P X-W L_{x}-r K_{x}\right)+\left(P^{*} X^{*}-W^{*} L_{x}^{*}-r^{*} K_{x}^{*}\right)
$$

where $P$ stands for the relative price of $X$.

We assume that $K_{x} K_{y}$ are specific to each sector. Labor is the only nonspecific and mobile factor between the two sectors within each nation, so that only one wage rate prevails within each country. Taking product and factor prices as given, the multinational firms maximize their profits when,

and,

and

$$
\begin{gathered}
P X_{L}\left(K_{x}, L_{x}, S\right)=W_{x} \\
P^{*} X_{K}^{*}\left(K_{y}^{*}, L_{x}^{*}, S^{*}\right)=W_{x}^{*}
\end{gathered}
$$

$$
\begin{gathered}
P X_{K}\left(K_{y}, L_{y}, S\right)=r_{y} \\
P^{*} X_{K}^{*}\left(K_{x}^{*}, L_{x}^{*}, S^{*}\right)=r_{x}^{*}
\end{gathered}
$$


Similarly, profit maximization on the part of local firms yields,

$$
\begin{aligned}
& Y_{L}\left(K_{x}, L_{x}\right)=w_{x} \\
& Y_{L}^{*}\left(K_{y}^{*}, L_{y}^{*}\right)=w_{y}^{*}
\end{aligned}
$$

and,

$$
\begin{aligned}
& Y_{L}\left(K_{y}, L_{y}\right)=r_{y} \\
& Y_{K}^{*}\left(K_{y}^{*}, L_{y}^{*}\right)=r_{y}^{*}
\end{aligned}
$$

Given that labor is mobile in each country, we have,

$$
W_{x}=W_{y}=W \text { and } W_{x}^{*}=W_{y}^{*}=W^{*}
$$

However, since capital is industry specific within each country, $r_{y} \neq r_{y}^{*}$; on the other hand, $r_{x} \neq r_{x}^{*}$, because capital stock owned by global firms is internationally mobile.

The labor market equilibrium conditions between the two sectors in each country is given by (5) and (6), so that,

$$
\begin{gathered}
P X_{L}\left(K_{x}, L_{x}, S\right)=Y_{L}\left(K_{y}, L_{y}\right) \\
P^{*} X_{L}^{*}\left(K_{x}^{*}, L_{x}^{*}, S^{*}\right)=Y_{L}^{*}\left(K_{y}^{*}, L_{y}^{*}\right)
\end{gathered}
$$

From (5') and (6') we obtain the equilibrium condition for the allocation of global firm's capital stock between the two countries, so that,

$$
P X_{K}\left(K_{x}, L_{x}, S\right)=P^{*} X_{K}^{*}\left(K_{x}^{*}, L_{x}^{*}, S^{*}\right)
$$

With full employment of labor in each country, we have by definition,

$$
L_{x}=L_{y}=\bar{L} \text { and } L_{x}^{*}=L_{y}^{*}=\bar{L}^{*}
$$

And, given the stock of capital owned by the global firms, it follows that,

$$
K_{x}+K_{x}^{*}=\bar{K}_{x}
$$

With this last equation the description of the model is complete. In this model we have six variables $\left(K_{x}, L_{x}, K_{x}^{*}, L_{x}^{*}, L_{y}, L_{y}^{*}\right)$ and eight parameters $\left(S_{x}, S^{*}, K_{y}, K_{y}^{*}\right.$, $\bar{L}, \bar{L}^{*}, \bar{K}_{x}, P$ and $\left.P^{*}\right)$. Following Batra and Ramachandran (1980), the global firms sell their goods in countries where they operate and to the rest of the world at international terms of trade $(P)$ which are assumed to be constant. If there is free 
trade, $P=P^{*}$; otherwise, $P$ and $P^{*}$ are linked by policy parameters such as tariffs, quotas, etc.

\section{Factor Supply and Multinational Firms}

The model can now be used to explore the impact of the multinational corporations on the host (source) country's sectoral level of employment, allocation of capital, factor rewards vis-à-vis a change in factor endowments in the host country, as well as, the source country. From the twelve equations presented in the previous section, those of immediate need are (8), (9) and (10). Totally differen-tiating these with appropriate substitutions, and assuming for simplicity $P=P^{*}=1$, initially, we obtain the following system of equations in matrix form,

$$
\left[\begin{array}{ccc}
\left(X_{L L}^{*}+Y_{L L}^{*}\right) & X_{K L}^{*} & 0 \\
0 & -X_{K L} & \left(X_{L L}^{*}+X_{L L}\right) \\
X_{K L}^{*} & \left(X_{K K}^{*}+X_{K K}\right) & -X_{K L}
\end{array}\right]\left[\begin{array}{l}
d L_{x}^{*} \\
d K_{x}^{*} \\
d L_{x}
\end{array}\right]=\left[\begin{array}{c}
Y_{L L}^{*} d \bar{L}^{*} \\
Y_{L L} d \bar{L}-X_{K L} d \bar{K}_{x} \\
X_{K K} d \bar{K}_{x}
\end{array}\right]
$$

The determinant of this system is given by,

$$
D=-\left[\left(X_{L L}^{*}+Y_{L L}^{*}\right)\left(G_{x}+X_{K K} Y_{L L}\right)+\left(X_{L L}+Y_{L L}\right)\left(G_{x}^{*}+X_{K K}^{*} Y_{L L}^{*}\right)\right]
$$

Where, in view of our assumptions about the production functions, $G_{x}>0 ; G_{x}^{*}>0$ and hence, $D$ is unambiguously positive.

The solution of this system yields,

$$
\begin{aligned}
\left(d L_{x}^{*} / d \bar{L}^{*}\right)= & (-1 / D)\left\{Y_{L L}^{*}\left[G_{x}+X_{K K}^{*}\left(X_{L L}+Y_{L L}\right)+X_{K K} Y_{L L}\right]\right\} \\
& \left(d L_{x}^{*} / d \bar{L}\right)=(1 / D)\left\{Y_{L L} X_{K L}^{*} X_{K L}\right\}
\end{aligned}
$$

and,

$$
\begin{aligned}
\left(d L_{x} / d \bar{L}\right)= & (-1 / D)\left\{Y_{L L}\left[X_{L L}^{*} X_{K K}+Y_{L L}^{*}\left(X_{K K}^{*}+X_{K K}\right)+G_{x}^{*}\right]\right\} \\
& \left(d L_{x} / d L^{*}\right)=(1 / D)\left\{Y_{L L}^{*} X_{K L} X_{K L}^{*}\right\}
\end{aligned}
$$

From our assumptions about production functions, it is clear from (15)-(18) that $\left(d L_{x}^{*} / d \bar{L}^{*}\right)$ and $\left(d L_{x} / d \bar{L}\right)$ are positive; whereas, $\left(d L_{x}^{*} / d \bar{L}\right)$ and $\left(d L_{x} / d \bar{L}\right)$ are negative. In addition, we can write, $\left(d L_{y} / d \bar{L}\right)=\left[1-\left(d L_{x} / d \bar{L}\right)\right]$ which provides,

$$
\left(d L_{y} / d \bar{L}\right)=(-1 / D)\left[\left(X_{L L}^{*}+Y_{L L}^{*}\right) G_{x}+X_{L L}^{*}\left(G_{x}^{*}+X_{K K}^{*} Y_{L L}^{*}\right)\right]
$$


and similarly,

$$
\left(d L_{y}^{*} / d \overline{L^{*}}\right)=(-1 / D)\left[X_{L L}^{*}\left(G_{x}+X_{K K} Y_{L L}\right)+G_{x}^{*}\left(X_{L L}+Y_{L L}\right)\right]
$$

It may be observed from (19) and (20) that $\left(d L_{y} / d \bar{L}\right)$ and $\left(d L_{y}^{*} / d \vec{L}^{*}\right)$ are positive. From all this we conclude that as $\bar{L}$ rises, $L_{x}$ and $L_{y}$ both rise, i.e. a rise in the labor supply in the source country raises labor employment in both its sectors. This is because as $\bar{L}$ rises, the real wage falls. This is clear from the fact that, $d W=Y_{L L} d L_{y}<0$ for $d L_{y}>0$. With the real wage falling, both sectors end up using more labor. This increase in employment in both sectors increases the marginal product of capital and in the case of the multinational sector it will induce an inflow of capital. In other words, if labor supply rises in the host country, it attracts the multinational capital while the source country loses capital. The reason is that as $\overline{L^{*}}$ rises, $W^{*}$ falls, but $r_{x}^{*}$ rises, inducing capital to move from the source to the host country.

Furthermore, from (13), we have,

$$
\left(d K_{x}^{*} / d \bar{L}^{*}\right)=(1 / D)\left\{X_{K L}^{*} Y_{L L}^{*}\left(X_{L L}+Y_{L L}\right)\right\}
$$

and,

$$
\left(d K_{x}^{*} / d \bar{L}\right)=(-1 / D)\left\{Y_{L L} X_{K L}\left(X_{L L}^{*}+Y_{L L}^{*}\right)\right\}
$$

It is fairly obvious that $\left(d K_{x}^{*} / d \bar{L}^{*}\right)$ is positive; whereas, $\left(d K_{x}^{*} / d \bar{L}\right)$ is negative. Given these results, the following theorems are then immediate.

Theorem I: A rise in the labor supply in one country raises labor employment in both its sectors; it also attracts multinational capital from the other country.

Theorem II: A rise in the supply of labor in one country raises the output of both goods in that country but reduces the output of the multinational sector in the other country and raises the local sector's output in the other country.

Our results in Theorem II are quite different from the Rybczynski Theorem traditionally discussed in the H-O model. In that model, an increase in the supply of labor will expand one sector at the expense of the other. In the present model, an increase in the labor supply will expand both sectors. Most importantly, the interrelationship between events in the source country and events in the host 
country hinges on the international transfer of capital. This adjustment can be analyzed as a two-stage process. Stage I includes the immediate and causative changes in the host country; while Stage II encompasses the impact attributable to the international relocation of capital. In Stage I, the host country experiences an increase in the labor supply, $\bar{L}^{*}$. This causes a fall in that nations wage rate and an expansion in both $X^{*}$ and $Y^{*}$. With the expansion in the labor force there is a concurrent rise in the marginal product of capital, raising both $r_{x}^{*}$ and $r_{y}^{*}$. It should be noted that in a specific factor model without multinationals both sectors will also expand when labor supply is increased.

Before the expansion of the labor supply in the host country, $r_{x}^{*}$ was equal to $r_{x}$. In Stage II, the temporary rise in $r_{x}^{*}$ above $r_{x}$ attracts capital away from the source and toward the host country. The departure of $K_{x}$ from the source country discourages the production of $X$ (manufacturing), and lowers the wage rate, $w$, in that country. Given the corresponding drop in the real wage in the multinational sector, there is an incentive for labor to leave this sector and migrate toward the local sector. This encourages an expansion in $Y$ (services). Hence, multinational firms reduce both the rate of manufacturing output, $X$, and manufacturing employment, $L_{x}$, in the source country.

The global movement of capital will internationally equilibrate the rental rate of capital in the multinational sector. Therefore, the movement of capital toward the host country will partially mitigate the decline in the nations real wage. However, the net result on factor allocation, wages and output is as stated in Stage I. This is because the arrival of capital in the source country is dependent on $w^{*}$ falling. Although the arrival of capital in Stage II in sector $X^{*}$ tends to raise $w^{*}$, it cannot raise it to its former level. The net result is that $X^{*}$ and $Y^{*}$ both expand, while $X$ contracts and $Y$ expands.

Given the industry-specific nature of capital in the services sector, the rental rate of capital need not be the same in both the manufacturing and the services sector in either nation. However, with the fall in the real wage in both nations, the marginal product and the rental rate of local firm capital should rise.

Theorems I and II are consistent with the stylized facts presented at the beginning of this paper. However, policies that promote the accumulation of capital by multinationals may mitigate the intersectoral changes. This can be observed by examining the output effect of the stock of capital owned by multinational firms. From the matrix system (13) we obtain, 


$$
\begin{gathered}
\left(d L_{x}^{*} / d \overline{K_{x}}\right)=(1 / D)\left\{G_{x} X_{K L}^{*}+Y_{L L} X_{K K} X_{K L}^{*}\right\} \\
\left(d K_{x}^{*} / d \overline{K_{x}}\right)=(-1 / D)\left\{\left[G_{x}+X_{K K} Y_{L L}\right]\left(X_{L L}^{*}+Y_{L L}^{*}\right)\right\}
\end{gathered}
$$

and,

$$
\left(d L_{x} / d \overline{K_{x}}\right)=(1 / D)\left\{X_{K L}\left[G_{x}^{*}+Y_{L L}^{*} X_{K K}^{*}\right]\right\}
$$

Given that cross partials of production functions are positive and own partials are negative, $\left(d L_{x}^{*} / d \bar{K}_{x}\right),\left(d K_{x}^{*} / d \bar{K}_{x}\right)$ and $\left(d L_{x} / d \bar{K}_{x}\right)$ are positive. The following theorem is immediatley available.

Theorem III: An increase in the stock of capital owned by the multinational firms leads to a rise in the employment of labor in multinational sectors in both countries. Similarly, the employment of capital also rises in the multinational sectors.

The intuitive explanation of this result is that a rise in the multinational capital stock lowers the rental rate and employs more capital in both $X$ and $X^{*}$. This raises the marginal product of labor in the multinational sectors, thereby raising the real wage in both countries. Labor, of course, then must move from $Y$ to $X$ and $Y^{*}$ to $X^{*}$. The following result is now in order.

Theorem IV: A rise in the supply of multinational capital raises the multinational output and reduces the local sector's output in both countries.

\section{Some Concluding Remarks}

The results derived in the previous section help explain the stylized facts listed at the beginning of this paper. Many economists have recently noted a decline in the real wage in the United States since 1973, as well as, a fall in the employment in the manufacturing sector, much of which is now dominated by the multinational corporations. In this paper, we have shown that if labor supply rises in the host country, capital moves from the source country to the host country, and this causes a fall in the source country's real wage, as well as, a fall in manufacturing employment.

The industrialized nations being the home of many multinational firms may be identified with the source country, whereas, the host country may be identified 
with the Third World in which the multinational firms are increasingly locating their new operations. Since labor supply in the Third World is growing much faster than in the industrialized nations, the relevance of our model to the real wage puzzle becomes obvious. Stated another way, one reason why manufacturing employment and real wages have been falling in the industrialized nations in the last several years is the sharply higher labor growth in the Third World.

The major portion of foreign direct investment occurs among the developed nations. Consequently, it may be argued that the capital flows between the industrialized and the developing nations are not large enough to produce the effects indicated in this paper. This is an empirical question. The impact will depend upon the influence of a marginal change in the investment flow. It is the marginal investment that determines the rental rate of capital.

The results of our model are also consistent with observed sectoral changes across countries. United Nations (1993) data on 120 countries over the years 1980 to 1991 indicate that employment growth was more rapid in developing nations and that the manufacturing employment grew at a more rapid pace in developing nations. Australia, Japan, and nations in North America and Western Europe has an average annual rate of growth in employment of $1.16 \%$, and an average annual rate of growth in manufacturing of $-.87 \%$. This can be compared with all other nations in the U.N. sample that had a $2.97 \%$ average annual rate of growth in employment and a $3.1 \%$ average annual increase in manufacturing employment.

The predictions that flow from the current model are also consistent with several trends that have been discussed in the literature. In the U.S. there has been growing income inequality between skilled and unskilled workers and a decline in production to non-manufacturing workers. ${ }^{5}$ The causes of these changes have been highly controversial and have resulted in some strident arguments. An examination of these arguments would fall outside the scope of this paper. Our model assumes a common equilibrium wage for both sectors. However, a logical extension suggests an alternative explanation for the observed trends. The movement of capital and technology from the slower growing source nations to the developing host nations could explain the observed shifts. As mobile capital migrates toward the host country, the demand for cofactors in source countries should decline. If we assume that the primary cofactors are production workers and unskilled workers, then the downward trend in numbers and wages is

${ }^{5}$ The data on these trends and the various explanatory causes have been debated widely in the economic literature. 
consistent with the models predicted movement of international capital.

The present model is meant to highlight the relationship between the flow of multinational capital and international labor growth. As such, we have attempted to construct a simple model that includes only the basic essentials required by this analysis. Within the context of the current model, the robustness of these predicted trends is yet to be examined. For example, we have assumed full employment of labor and the free flow of multinational capital. Given the presence of market imperfections and protectionist economic policies, these assumptions need to be relaxed. Future additions to the model may include a variable labor supply, endogenous prices and trade barriers. It remains to be demonstrated whether each or all of the additions may either reinforce or mitigate the predicted result.

\section{Acknowledgement}

We are indebted to Ronald Jones and two anonymous referees for valuable comments and suggestions on an earlier version of this paper. Any errors and omissions are our responsibility.

Date accepted: 18 May 2000

\section{References}

Batra, Ravi, (1986), “A General Equilibrium Model of Multinational Corporations In Developing Countries", Oxford Economic Papers, 38, 342-53. (1992), "The Fallacy of Free Trade", Review of International Economics, 19-

32.

Batra, R.N. and R. Ramachandran (1980), "Multinational Firms and the Theory of International Trade and Investment", American Economic Review, 70(3), June, 278-290. Beladi, Hamid and Sugata Marjit (1994), "Capital Mobility and Import Substitution Policies", Journal of International Trade and Economic Development, 3(3), November, 269-275. (1996), "An Analysis of Rural-Urban Migration and Protection”, Canadian Journal of Economics, 29(4), 930-940.

Chao, Chi-Chur and E. S. H. Yu (1992), "Capital Markets, Urban Unemployment And Land”, Journal of Development Economics, April, 407-413.

(1990), "Urban Unemployment, Terms of Trade and Welfare", Southern Economic Journal, 5, 1-15.

Jones, Ronald W. (1967), "International Capital Movements and the Theory of Tariffs and 
Trade", Quarterly Journal of Economics, 1-38.

(1971), "A Three Factor Model in Theory, Trade and History", in Jagdish Bhagwati, et al., eds., Trade, Balance of Payments and Growth: Essays in Honor of C. P. Kindleberger, Amsterdam, 3-21.

Jones, Ronald W. and Stanley L. Engerman (1996), "Trade, Technology and Wages: A Tale of Two Countries", American Economic Review, 86(2), May, 35-40.

Krugman, Paul (1995), "Growing World Trade: Cause and Consequences", Brookings Papers on Economic Activity, 1, 327-377.

Marjit, Sugata and Hamid Beladi (1997), “An Analysis of Optimal Size for a Special Economic Zone”, Swiss Journal of Economics and Statistics, 133(2-1), June, 153-164. (1996), "Protection and the Gainful Effects of Foreign Capital", Economics Letters, 53(3), December, 311-316.

Markusen, James R. (1995), "The Boundaries of Multinational Enterprises and The Theory of International Trade", Journal of Economic Perspectives, 9(2), Spring, 169189.

U. N. Department of Economic and Social Information (1993), Statistical Yearbook: 1990-91, Information on Policy Analysis, Statistical Division, United Nations: New York.

U. S. Department of Commerce (1993), Statistical Abstract of the U. S.: 1993, Bureau of the Census, Economics and Statistics Administration, CD-ROM.

Yu, E. S. H. (1982), "Unemployment and the Theory of Customs Union”, The Economic Journal, 32, 399-404.

(1985), "Toward a Theory of Customs Unions with Foreign Investments", Economia Internazionale, 38(2), 222-235. 